Estudios Constitucionales, Año 10, No 2, 2012, pp. 617 - 642.

ISSN 0718-0195

Centro de Estudios Constitucionales de Chile Universidad de Talca

"35 Años del recurso de protección

notas sobre su alcance y regulacion normativa”

Enrique Navarro Beltrán

\title{
35 AÑOS DEL RECURSO DE PROTECCIÓN NOTAS SOBRE SU ALCANCE Y REGULACIÓN NORMATIVA
}

\author{
35 YEARS OF PROTECTION ACTION \\ (Notes AbOUT THE SCOPE AND REgUlATION RULES)
}

EnRique NaVARro BeLTRÁN ${ }^{1}$

Profesor de Derecho Constitucional

Universidad de Chile

El año pasado, y sin que nadie lo consignara de manera especial, en forma silenciosa, como suele ocurrir en nuestro país, se conmemoraron los 35 años del recurso de protección, acción cautelar establecida por primera vez en el Acta Constitucional de 1976 y que hoy se contiene en el artículo 20 de la Constitución Política. ${ }^{2}$

En el presente artículo se analizarán los antecedentes históricos de esta acción cautelar constitucional, su importancia cuantitativa, la tendencia a la propietarización de los conflictos, la forma en que se ha dado tutela a derechos no protegidos y su regulación normativa.

\section{ANTECEDENTES HISTÓRICOS DE LA PROTECCIÓN}

El antecedente histórico de esta acción se remonta a las facultades protectoras de los tribunales de justicia y que ejercieron hasta 1874. Posteriormente,

\footnotetext{
${ }^{1}$ El autor es abogado, licenciado en Ciencias Jurídicas y Sociales (U. de Chile). Profesor Titular de Derecho Constitucional de la U. de Chile, siendo Director del Departamento de Derecho Público, desde 2003. Profesor Titular de Derecho Constitucional de la U. Finis Terrae, donde es Director de Investigación y de la Revista de Derecho de la UFT. Ha sido Director de Estudio de la Corte Suprema (2002-2006) y Ministro del Tribunal Constitucional (2010-2012).

${ }^{2}$ Un análisis de las tres primeras décadas, Navarro Beltrán, Enrique, 30 años del Recurso de Protección, en Libro Homenaje a Mario Verdugo Marinkovic, Editorial Jurídica (2009); pp. 141-154. En relación a los primeros 20 años vid. Sото KLoss, El recurso de protección, institución esencial de una sociedad libre, en 20 años de la Constitución Chilena 1981-2001, Santiago (2001), Ed. Navarro B., Enrique, pp. 421 y ss.
} 
y por casi un siglo, el único mecanismo tutelar en nuestro país lo constituirá el hábeas corpus. ${ }^{3}$ En Hispanoamérica también puede citarse el amparo mexicano, de mediados del siglo XIX, que hoy día se extiende bajo diversas modalidades en toda la región. ${ }^{4}$

Se trata de que existan mecanismos que garanticen efectivamente los derechos, evitando que éstos sólo sean meras declaraciones. En efecto, tal como lo consigna el Acta Constitucional que establece la protección, "por muy perfecta que sea una declaración de derechos éstos resultan ilusorios si no se consagran los recursos necesarios para su debida protección". 5

Puesto que, como nos lo recuerda Calamandrei, todas las declaraciones constitucionales son fútiles, si no existen medios jurídicos procesales que aseguren su eficacia real. ${ }^{6}$

\section{IMPORTANCIA DE LA ACCION CAUTELAR}

Como lo ha señalado reiteradamente la Corte Suprema, se trata de una acción cautelar ${ }^{7}$, destinada a amparar el legítimo ejercicio de derechos preexistentes $^{8}$, mediante la adopción de medidas de resguardo 9 frente a actos u omisiones ilegales o arbitrarias que impida, amague o moleste el mismo. ${ }^{10}$

\footnotetext{
${ }^{3}$ Vid. Navarro Beltrán, Enrique, La Judicatura chilena: del Absolutismo Ilustrado al Estado Constitucional (1987).

${ }^{4}$ Ferrer Mac-Gregor, Eduardo, "El Amparo Iberoamericano", CECOCH 4 No 2, (2006), pp. 39 y ss.

${ }^{5}$ Acta Constitucional 3.

${ }^{6}$ Calamandrei, cit. por Colombo Campbell, Juan, "El debido proceso constitucional", Cuadernos del Tribunal Constitucional 32, (2006), p. 52.

7 Sobre la materia vid. Soto Kloss, Eduardo, El Recurso de Protección, Ed. Jurídica, 1982; Zavala, José Luis, Recurso de protección, casos y jurisprudencia, Ed. PuntoLex, 2009, 4 tomos; Gómez Bernales, Gastón, Derechos fundamentales y recurso de protección, Ed. UDP, 2005; NogueIra AlCALÁ, Humberto, Acciones constitucionales de amparo y protección, realidad y prospectiva en Chile y América Latina, Ed. U. Talca, 2000; Errázuriz Gatica, Juan Manuel y Otero Alvarado, Jorge Miguel, Aspectos procesales del recurso de protección, Ed. Jurídica, 1989.

${ }^{8}$ Corte Suprema, Rol No 2628-2011, 14.4.2011.

${ }^{9}$ El tribunal debe estar en condiciones de adoptar una medida. Así, se ha señalado que el recurso carecerá de su objetivo si "la Corte no se encuentra en situación de adoptar medida alguna para los efectos antes indicados" (Corte Suprema, Rol No 1827-2010, 24.05.2010).

${ }^{10}$ Corte Suprema, Rol No 6963-2010, 28.10.2010.
} 
Puede ser interpuesta por cualquier persona, sea ésta natural, jurídica o una agrupación ${ }^{11}$-aunque no se trata de una acción popular ${ }^{12}$ - y sin estar sujeta a mayores formalidades ${ }^{13}$.

\section{Aumento sostenido de las acciones}

En estos 35 años transcurridos, el incremento de las acciones ha sido ciertamente notable. De unas pocas decenas -a fines de los setenta- a más de 30.000 anuales -en la actualidad-y que se refieren diversas situaciones vinculadas a bienes jurídicos tan importantes como la vida, igualdad, privacidad, libertad y propiedad, siempre y cuando se trate de derechos indubitados. ${ }^{14}$

Para apreciar la magnitud de esta acción, es caso tener presente que sólo el año 2011, la Corte Suprema resolvió más de cinco mil apelaciones de protección, habiendo acogidos en definitiva cerca de un 75\%. En otras palabras, de cada cuatro acciones que fueron conocidas por el máximo tribunal, una fue aceptada, lo que constituye un porcentaje elevado si se lo compara con el de otros ordenamientos jurídicos, en donde sólo las inadmisibilidades bordean el $90 \% .^{15}$

${ }^{11}$ Corte Suprema, Rol No 3275-2006, 20.7.2006.

${ }^{12}$ La acción requiere de un interés directo e inmediato de parte de una persona específica y determinada, razón por la cual no constituye una acción popular (Corte Suprema, Rol No 1577-2011, 6.4.2011). De existir, por tanto, un perjudicado concreto (Corte Suprema, Rol No 2194-2011, 23.3.2012). Vid. la situación especial del derecho a la vida en Castellón Venegas, Hugo, Acción popular y recurso de protección, IP 4, No 6, 2001.

13 Corte Suprema, Rol No 2912-2010, 31.8.2010. Se han excluido de su alcance las materias de lato conocimiento propias de un juicio ordinario, como usualmente lo ha precisado el máximo tribunal (Corte Suprema, Rol No 1028-2012, 17.5.2012).

${ }_{14}$ Reiteradamente la Corte Suprema ha enfatizado que debe tratarse derechos indubitados (Rol No 2973-2012, 15.06.2012).

15 Vid. Informe de Dirección de Estudio de la Corte Suprema (2011). Del total de acciones acogidas, 3.805 corresponden a temas referidos a contratos de salud. Con mucho menor relevancia pueden citarse las presentaciones dirigidas contra la Inspección del Trabajo (23), Tesorería General de la República (17) y Municipalidades (35). A nivel de Cortes de Apelaciones, el ingreso nacional de recursos de protección ascendió a 32.045, de los cuales 25.778 corresponden a Santiago. Con muy menores ingresos pueden señalarse los casos de las Cortes de Concepción (1.842), Serena (911), Valparaíso (600) y Temuco (584). 


\section{Amplio ámbito de derechos fundamentales ${ }^{16}$}

Ciertamente, la dinámica protectora ha sido muy notable si se revisa la doctrina contenida en los fallos y que se aprecia en las decisiones en las que se tutela la vida ${ }^{17}$ y la integridad física y psíquica e incluso el derecho a vivir en un medio ambiente libre de contaminación ${ }^{18}$. Lo mismo puede decirse en relación a la igualdad ante la ley ${ }^{19}$ y la prohibición de ser juzgados por comi-

${ }^{16}$ Vid. Navarro Beltrán, Enrique, Derechos Fundamentales en Chile: evolución, alcance y protección, Fundaciones Konrad Adenauer, Friedrich Elbert, Heinrich Böll y Hanns Seidel, Editorial Jurídica, 2010; pp. 25-40.

17 En los años ochenta existen pronunciamientos en relación a huelgas de hambre (Corte de Apelaciones de Santiago, 9 de agosto de 1984, GJ 50, p. 76). En los años noventa destacan decisiones sobre negativa de pacientes para recibir transfusiones sanguíneas (Corte Suprema, 18 de enero de 1996, GJ 187, p. 62). A partir del 2000 surge controversia sobre la denominada "píldora del día después" (Corte Suprema, 30 de agoto de 2001, Rol No 2186-2001). El año 2011, la Corte Suprema acogió 25 recursos por vulneración del derecho a la vida, pudiendo citarse los casos de negativas a atención médica (Rol 8902-2010, 26.1.11) o de tratamiento (Rol No 1122-2011, 21.4.11), negativa de cuidados necesarios (Rol 606-2011, 27.1.11) o de reparaciones de bienes comunes (Rol No 2472-2011, 9.6.11) o huelga de hambre (Rol No 4167-2011).

${ }_{18}$ Vid. Navarro Beltrán, Enrique, "Recurso de Protección y derecho a vivir en un medio ambiente libre de contaminación”, RCHD 20, 1993, p. 595, y Bertelsen RepetTo, Raúl, "El recurso de protección y el derecho a vivir en un medio ambiente libre de contaminación”. Examen de 15 años de jurisprudencia, RCHD 25, 1998, p. 139. La jurisprudencia ha reconocido diversos tipos de contaminación: acústica, acuática, terrestre, atmosférica e, incluso, la visual. La reforma constitucional de 2005 precisó la procedencia del mismo contra actos u omisiones ilegales. En el ámbito ambiental son conocidas las más recientes acciones acogidas por distintas razones, exigiendo así -por ejemplo- a un proyecto someterse a un estudio de impacto ambiental (Rol No 5191/2011) o que se consulte a los pueblos originarios (Roles Nos. 258/2011 y 10090/2011). El año 2011 se acogieron 7 casos por parte de la Corte Suprema referidos a materia ambiental (Roles Nos. 6062-2010, 4.1.11; 4668-2010, 18.1 .11 ; 5191-2010, 18.1.11; 2115-2011, 28.4.11; 2217-2011, 10.6.11; 3984-2011, 17.6.11 y 11415-2011, 30.12.11).

${ }^{19}$ La igualdad, siguiendo al Tribunal Constitucional se ha entendido como dar el mismo trato a los que se encuentran en similar situación. En recientes fallos el TC también ha incorporado criterios referidos a la proporcionalidad y finalidad de la medida (Roles Nos. 755-2007 y 790-2007). De modo que lo que se prohíbe son las discriminaciones arbitrarias (Corte Suprema, 3 de junio de $1994, G J 168$, p. 81). Se han estimado como atentados a la igualdad ante la ley las resoluciones administrativas que limitan número de síndicos (Corte Suprema, 23 de mayo de 1995, GJ 180, p. 30) y aquella que niega autorización para instalar publicidad (Corte Suprema, 8 de abril de 1997, GJ 202, p. 47). El año 2011 se acogieron por parte de la Corte Suprema 44 recursos en que se invocó la igualdad ante la ley, pudiendo mencionarse situaciones tales como las de término anticipado de un contrato (Rol No 9625-2019, 18.1.11), negativa injustificada de ingreso a una institución pública (Rol No 691-2011, 4.05.11) o de otorgar certificados a estudiantes (Rol No 1258-2011, 7.4.11), desconocimiento de beneficios a funcionarios (Rol No 957-2011, 1.3.11), expulsión injustificada 
siones especiales. ${ }^{20}$ Interesante ha sido la confrontación entre la privacidad y la intimidad ${ }^{21}$ y la libertad de información. ${ }^{22}$ La libertad de conciencia ha tenido escasos pronunciamientos ${ }^{23}$. En materia de derecho de reunión y asociación destacan pronunciamientos sobre justicia doméstica. ${ }^{24}$ Además, deben resaltarse los derechos de contenido económico, como la libertad empresarial y la no discriminación en el trato económico. ${ }^{25}$

de asociación (Rol No 7731-2011, 5.9.11), modificaciones unilaterales de contratos (Rol No 13442011, 6.5.11) o un beneficio otorgado a un competidor (Rol No 4348-2011, 16.6.11). Una visión jurisprudencial en Navarro Beltrán, Enrique, Igualdad ante la ley y jurisprudencia del TC, en AJ 26, 2012, pp. 63-95.

${ }^{20}$ En esta materia se aprecian un sin fin de actuaciones, preferentemente administrativas, que importan una suplantación de las funciones jurisdiccionales propias de los tribunales. Vid. Corte Suprema, 25 de marzo de 1998, GJ 213, p. 179. Más recientemente, Corte Suprema, 27 de abril de 2005, Rol No $1226-2005$.

${ }^{21}$ Clásicos resultan los conflictos de derechos entre la libertad de expresión y la honra. Un caso paradigmático es el denominado "La última tentación de Cristo", Corte Suprema, 20 de enero de 1997, Rol No 519-97, en el que se prohibió la exhibición de la misma. Una forma diversa de resolver es el caso "Prat", donde se da preferencia más bien a la libertad de creación, Corte Suprema, 16 de julio de 1003, Rol No 1961-2003. Se trata más bien de una situación en que debe efectuarse un examen de ponderación de derechos.

${ }^{22}$ Los tribunales la han estimado como una de las libertades fundamentales, incluso en períodos complejos de nuestra historia. Vid. Corte de Apelaciones de Santiago, 12 de diciembre de 1980, RDJ 77, sec. $2^{\text {a }}$, p. 195. El Tribunal Constitucional ha señalado su alcance en los autos rol No 226, de 1995. Recientemente se ha reiterado que el acceso a la información es parte de la garantía constitucional (Rol No 634-2006).

${ }^{23}$ Un caso a mencionar es de la denominada “secta Moon", Corte Suprema, 15 de septiembre de 2005, No 2226-2005. Del mismo, la sentencia que se pronunció sobre la objeción de conciencia respecto del servicio militar (Corte de Apelaciones de Santiago, 27 de mayo de 2003, Rol No 1970-2003).

${ }^{24}$ Aquí pueden citarse la exclusión ilegal y arbitraria de asociaciones. Vid. Corte Suprema, sentencias de 10 de marzo de 2004, Rol No 378-04 y 21 de julio de 2004, Rol No 2729-04. El año 2011, puede citarse el caso de cobro de cuotas sociales por parte de un centro de apoderados de un establecimiento educacional (Rol 1469-2011, 24.3.11).

${ }^{25}$ Cabe señalar que en materia de libertad económica existe también una acción popular denominado "amparo económico". Sobre el punto vid. Navarro Beltrán, Enrique, "El recurso de amparo económico" (Notas sobre quince años de jurisprudencia), UFT 9 (2005). También en CECOCH, (2007), No 5 No 2, pp. 99-119. El año 2011, la Corte Suprema acogió 15 recursos de protección referidos al libre emprendimiento de actividades económicas, vinculados a prohibiciones de ingreso a caminos (Rol No 9603-2010, 27.1.11), negativa a renovar patentes comerciales municipales (Rol No 4002-2011, 1.6.11), prohibición de funcionamiento de local (Roles Nos. 5600-2011, 8.7.11 y 6801-2011, 13.9.11) o comunicaciones a Dicom de morosidad (Rol No 4058-2011, 3.8.11). 


\section{Exigencias constitucionales}

Como se sabe, la acción cautelar es procedente no sólo respecto de perturbaciones o privaciones de un derecho indubitado ${ }^{26}$ y preexistente ${ }^{27}$, sino también frente a amenazas. ${ }^{28}$

Por cierto, desde el punto de vista causal ${ }^{29}$, debe tratarse de actos u omisiones arbitrarias o ilegales, esto es, carentes de fundamento o contrarias a la ley, como lo ha afirmado reiteradamente la Corte Suprema. ${ }^{30}$

Cabe tener presente que la sentencia que se dicta en el proceso constitucional que motiva una acción de protección produce cosa juzgada formal. ${ }^{31}$

\section{Protección y debido proceso}

Del mismo modo, cabe tener presente que si bien tradicionalmente se ha entendido que no es la vía para impugnar decisiones judiciales, lo ha hecho en el entendido que se trata de una decisión motivada y razonable, escuchando a la parte ${ }^{32}$ e incluso ha dejado sin efecto una decisión en el marco de un procedimiento en el que no había sido oído el perjudicado, lo que "torna la sentencia en ilegal". ${ }^{33}$

\footnotetext{
${ }^{26}$ Corte Suprema, Rol No 1008-2011, 27.4.2011.

27 Corte Suprema, Rol No 2628-2011, 14.4.2011.

${ }^{28}$ Vid. Sото Kloss, Eduardo, El Recurso de Protección (1982) La amenaza debe ser "seria, directa y actual para los derechos esenciales" (Corte Suprema, Rol No 7562-2008, 26.1.2009).
}

${ }^{29}$ Como ha señalado la Corte Suprema, debe tratarse de "una relación causa-efecto" (Rol No 1827-2010, 24.5.2010.

${ }^{30}$ En tal sentido, Corte Suprema Rol No 1827-2010, 24.5.2010.

${ }^{31}$ En efecto, se ha sentenciado que "los recursos de protección sólo producen cosa juzgada formal, esta es, la que produce efecto dentro del proceso en que se dictó la resolución, pero no fuera de él - a diferencia de la cosa juzgada material, que produce efectos dentro y fuera del proceso-, pues no determinan la concurrencia exclusiva de derechos a favor del recurrente, sino procuran amparar al titular de un derecho de cuyo ejercicio se le priva, perturba o amenaza, en forma arbitraria o ilegal, el que podrá accionar con posterioridad ante el tribunal competente para que éste declare en carácter de inamovible la titularidad del derecho, circunstancia que obliga a desestimar la excepción de cosa juzgada". (Corte Suprema, Rol No 561/2007, sentencia que rechaza casación, respecto de sentencia de segunda instancia, Rol No 4148/2004, que hace suya la de primera instancia del $1^{\text {er }}$ Juzgado Civil de Viña del Mar, Rol No 2315/2001. Sobre la materia, Romero Seguel, Alejandro, "Notas sobre la cosa juzgada en el recurso de protección”, en RCHD 26, No 2, 1999.

32 Corte Suprema, Rol No 3065/2012.

33 Corte Suprema, Rol No 3557/2012. 
A su vez, aunque en estricto rigor el debido proceso no está amparado con la acción cautelar, ${ }^{34}$ se han dejado sin efecto actuaciones en las cuales se ha estimado que se ha pretendido transformar un órgano en un tribunal ${ }^{35} \mathrm{o}$ no se ha respetado el procedimiento previsto en los estatutos ${ }^{36} \mathrm{o}$ el administrativo $^{37}$. Incluso, ha existido una tutela a través del derecho de propiedad en relación a un procedimiento. ${ }^{38}$

Como ha señalado la Corte Suprema, en concordancia con el Tribunal Constitucional ${ }^{39}$, el derecho del debido proceso "a lo menos lo constituye un conjunto de garantías que la Constitución Politica de la República, los tratados internacionales ratificados por Chile y en vigor y las leyes le entregan a las partes de la relación procesal, por medio de las cuales se procura que todos puedan hacer valer sus pretensiones en los tribunales, que sean escuchados, que puedan reclamar cuando no están conformes, que se respeten los procedimientos fijados en la ley, que las sentencias sean debidamente motivadas y fundadas, entre otros". ${ }^{40}$

En diversos pronunciamientos el Tribunal Constitucional ha analizado el alcance del contenido del debido proceso, que se encuentra enunciado en el artículo 19 No 3 de la Constitución Política, inciso 5º, al señalar que le corresponde al legislador establecer siempre "las garantías de un procedimiento y una

\footnotetext{
${ }^{34}$ A pesar del tenor literal del artículo 20, la jurisprudencia de los tribunales superiores de justicia ha sido amplia en el sentido de la procedencia de la acción de protección respecto de actos que no se ajusten a un debido proceso. Incluso se ha invocado el derecho de propiedad. Sobre el punto vid. VARAS A., Paulino y Mohor A., Salvador, "Procedencia del recurso de protección frente a las disposiciones del artículo 19 No 3 de la Constitución”, en RCHD, Ed. Especial, 1998, pp. 279-300.

${ }^{35}$ El año 2011, la Corte Suprema acogió 40 casos, invocando la garantía de no ser juzgado por comisiones especiales, pudiendo destacarse los casos de interpretación de cláusulas contractuales por la Inspección del Trabajo (Roles $\mathrm{N}^{\circ}$ s. 4462-2011, 5.7.11 y 7344-2011, 5.10.11) o la prensión administrativa de aplicar sanciones (Rol No 9242-2010, 25.11.11) o de manera errónea (Rol No 352-2011, 28.1.11). Igualmente, pueden mencionarse de conductas de particulares, como por ejemplo, la publicación de morosidad sin ajustarse al procedimiento (Rol No 9306-2010, 7.1.11), interpretación de cláusulas contractuales (Rol No 9630-2010, 27.1.11) o actos de autotutela (Rol No 9767-2011, 8.9.11).

${ }^{36}$ Corte Suprema, Rol No 3277/2012.

${ }^{37}$ Corte Suprema, Roles Nos. 3434-2011, 11.5.11 y 3666-2011, 18.5.11.

${ }^{38}$ Respecto de negativa de revisar procedimiento en que se aplicó una multa, Corte Suprema, Rol No 10084-2011, 25.1.11.

39 Navarro Beltrán, Enrique, “Debido Proceso y Jurisprudencia del TC", en Litigación Pública, 2010.

${ }^{40}$ Corte Suprema, Rol No 990/2010.
} 
investigación racionales y justos" ${ }^{41}$, haciéndolo obviamente aplicable también al derecho administrativo sancionador ${ }^{42}$, aunque se trate de actuaciones administrativas. ${ }^{43}$

Sobre este último punto, se ha precisado que "aunque se trate de potestades que no suponen ejercicio de jurisdicción, ciertamente deben sujetarse a los parámetros propios de un debido proceso" ${ }^{\text {"44. }}$. En concordancia con lo anterior, respecto al ámbito de aplicación de la garantía, se ha señalado que ella dice relación con el ejercicio de la función jurisdiccional, independiente del órgano que la ejerza, siendo una cuestión de mérito, que escapa al control de constitucionalidad, la elección por parte del legislador respecto del órgano que la ejerza. ${ }^{45}$ De esta forma, para dictar el acto administrativo sancionador se ha destacado la importancia de haber "previamente escuchado a la parte afectada" y, eventualmente, recibir "antecedentes probatorios" 46 . Se exige entonces que "el acto administrativo sancionador se imponga en el marco de un debido proceso". ${ }^{47}$

\section{Protección y órganos autónomos}

Igualmente se ha dejado sin efecto actuaciones de órganos constitucionales autónomos. Así, se ha precisado ${ }^{48}$ las situaciones que pueden justificar

\footnotetext{
${ }^{41}$ Navarro Beltrán, Enrique, "Debido Proceso y ejercicio de facultades por parte de la Superintendencia de Servicios Sanitarios”, RDP 66 (2004), pp. 97-119.

${ }^{42}$ Un análisis más detallado en Navarro Beltran, Enrique, "Principios que rigen en materia de derecho administrativo sancionador reconocidos por la jurisprudencia chilena", en obra colectiva: Nullum crimen, nulla poena sine lege, Homenaje a grandes penalistas chilenos, Ed. UFT, 2010, pp. 241-265.

${ }^{43}$ El Tribunal ha señalado que, "aunque se trate de potestades que no suponen ejercicio de jurisdicción, ciertamente deben sujetarse a los parámetros propios de un debido proceso" (Rol No 766, consid. 12). Por lo mismo, para dictar el acto administrativo sancionador se ha destacado la importancia de haber "previamente escuchado a la parte afectada" y, eventualmente, recibir "antecedentes probatorios" (Rol No 766, consid. 25). Igualmente, debe existir "la posibilidad de impugnar el acto administrativo ante los tribunales" (Roles Nos. 766, de 25 de junio de 2008, y 1223, de 30 de diciembre de 2008). Se exige entonces que "el acto administrativo sancionador se imponga en el marco de un debido proceso" (Rol No 1233 , de 13 de enero de 2009).

${ }^{44}$ Rol No 766, 25 de junio de 2008, consid. 12.

45 Rol No 616, de 6 de septiembre de 2007.

${ }^{46}$ Ibid., consid. 25.

${ }^{47}$ Rol No 1233 , de 13 de enero de 2009.

48 Un análisis de la jurisprudencia en Navarro Beltrán, Enrique, "Bases constitucionales de la potestad dictaminante de la CGR", en Libro homenaje a los 85 años de la CGR, 2012.
} 
una revisión judicial de dictámenes emanados de la Contraloría General de la República. ${ }^{49}$

Del mismo modo, se han estimado arbitrarios e ilegales actuaciones municipales que deniegan solicitudes sin encontrarse debidamente motivadas. ${ }^{50}$

\section{PROTECCIÓN Y PROPIEDAD}

Este es por lejos el derecho constitucional más invocado en los recursos de protección.

En efecto, es el más citado en los fallos de la Corte Suprema para el período 2004-2005 ${ }^{51}$ e igualmente el año 2011.52 Durante el año 2004, en 139 casos el derecho más vulnerado fue el derecho de propiedad, aunque el total de casos en que esta aparece afectada asciende a la cantidad de 178. En tanto, el año 2005 se acogieron 162 recursos por infracción al artículo 19 No 24 de la Constitución. En 127 se estimó vulnerado sólo este derecho constitucional, mientras que en los 35 restantes se consideró afectada además alguna otra garantía: en diez, el derecho a no ser juzgado por comisiones especiales; en seis, la igualdad ante la ley; en otras seis, el derecho a la vida; en cinco, la libertad económica; en tres, la libre elección del sistema de salud; y en uno la libertad de trabajo. Además, en cuatro ocasiones concurrió el derecho de propiedad junto con otras dos garantías.

El crecimiento ha sido exponencial, si se piensa que durante el año 2011, la Corte Suprema acogió casi 4.000 casos vinculados a la afectación al derecho de propiedad.

Los recursos de protección acogidos por la Corte Suprema en resguardo de este derecho, lo fueron tanto en la propiedad recaída sobre cosas corporales, como sobre cosas incorporales e, incluso, sobre derechos de contendido patrimonial, según pasamos a revisar a continuación:

\footnotetext{
${ }^{49}$ Corte Suprema, Rol No 2791/2012.

${ }^{50}$ Corte Suprema, Rol No 3540/2012.

51 Vid. Navarro Beltrán, Enrique, "La Constitucionalización del Derecho a la luz de la jurisprudencia de la Corte Suprema”, Revista UM 3 (2004), pp. 97-122. También, Constitucionalización del Derecho Civil: la protección sobre las cosas incorporales. En obra conmemorativa de 150 años del Código Civil (2005), Editorial LexisNexis, pp. 517-531.

52 Vid. Informe de la Dirección de Estudio de 2011.
} 


\section{Propiedad sobre cosas corporales}

Un alto número de los recursos acogidos por esta causal lo fueron por vulneraciones al derecho de propiedad sobre bienes físicos, tales como cierres de caminos y predios e impedimentos al ejercicio de servidumbres, ${ }^{53}$ de acceso a un determinado bien ${ }^{54}$ o de realizar trabajos en una propiedad..$^{55}$

Del resto de los recursos acogidos por este motivo, se observan las más diversas causas y contextos fácticos. Así, por ejemplo, encontramos recursos por uso ilegal de bienes nacionales de uso público ${ }^{56}$, introducción de animales en predios ajenos ${ }^{57}$, negativa de un Director de Obras Municipal a autorizar la división de un predio ${ }^{58}$, solicitudes de inscripción de dominio que afecta derechos de terceros ${ }^{59}$, suspensiones de obras que amenazan integridad física de vecinos ${ }^{60}$, afectación de tenencia de bienes ${ }^{61}$, ocupación de inmueble sin título legal ${ }^{62}$, compensaciones improcedentes de tributos ${ }^{63}$, reducción ilegal de pensiones ${ }^{64}$, entre otros.

\section{Propiedad sobre cosas incorporales}

La mayor parte de los recursos acogidos por la Corte Suprema en razón de vulneraciones al derecho de propiedad, estuvieron referidos a tal derecho sobre cosas incorporales. A su vez, en parte importante de los recursos

\footnotetext{
${ }^{53}$ Véase por ejemplo Roles $\mathrm{N}^{\circ}$ s. 80-2004, 1340-2004, 5863-2004, 3059-205, 2044-2005 y, más recientemente, 5201-2007. Más recientemente, Rol No 454-2011, 27.1.11. Tratándose del no respeto de servidumbres legalmente constituidas, puede citarse los Roles $\mathrm{N}^{\circ}$ s. 9902-2011, 14.3.11; 1954-2011, 31.3.11; 1334-2011, 13.4.11 y 6122-2011, 29.8.11.

${ }^{54}$ Roles Nos. 2765-2011, 29.4.11; 2155-2011, 28.4.11; 3029-2011, 20.5.11 y 10610-11, 12.12.11.

55 Roles Nos. 9946-2010, 14.3.11; 2472-2011, 9.6.11 y 6303-11, 2.8.11.

${ }^{56}$ Corte Suprema, Rol No 5597-2005.

57 Corte Suprema, Rol No 6205-2005.

58 Corte Suprema, Rol No 5504-2005.

59 Corte Suprema, Rol No 5570-2003.

${ }^{60}$ Corte Suprema, Rol No 1685-2006.

${ }^{61}$ Corte Suprema, Rol No 6710-2005. Más recientemente, Rol No 4619-2011.

${ }^{62}$ Corte Suprema, Roles Nos. 1436-2011, 25.3.11; 2509-2011, 9.6.11, y 10786-2011, 30.11.11.

${ }^{63}$ Corte Suprema, Rol No 1698-2006.

${ }^{64}$ Corte Suprema, Rol No 5441-2006.
} 
presentados, las recurridas fueron Isapres, respecto de las cuales los afiliados alegaron atentados a su derecho de propiedad sobre beneficios emanados de los correspondientes contratos de salud. Sólo en el año 2004, 60 de los 139 recursos acogidos por esta garantía dijeron relación con alzas en planes de salud por parte de dichas Instituciones, negativa a dar cobertura o término unilateral del contrato de salud. No obstante lo anterior, hubo más recursos acogidos en contra de las Isapres por vulneración de esta especie de propiedad, pero en complemento de otros derechos constitucionales como los de los números 1 y 9 del artículo 19. El año 2011, como ya se ha señalado, de las 4.028 protecciones acogidas, 3.805 corresponden a temas de salud.

De todos los recursos acogidos en contra de las Isapres, se sentó una rica jurisprudencia en relación con los contratos y planes de salud, que se puede resumir en los siguientes criterios: a) Los motivos que justifican la revisión de un plan de salud por parte de las Isapres deben interpretarse restrictivamente ${ }^{65}$; b) Es arbitrario alzar un plan de salud sin antecedentes que lo justifiquen y, a la vez, sin mejorar las prestaciones ${ }^{66}$; c) La facultad de la Isapre de revisar el plan de salud debe ser motivada de acuerdo a criterios de razonabilidad ${ }^{67}$, y d) La facultad de la Isapre de reajustar en plan de salud, conforme a lo dispuesto en el inciso tercero del artículo 38 de la Ley de No 18.933, debe condicionarse a un cambio efectivo del costo de las prestaciones médicas ${ }^{68}$.

El resto de los recursos acogidos por vulneración del derecho de propiedad sobre cosas incorporales han tenido las más variadas causas y antecedentes: derechos que emanan de un contrato de arrendamiento ${ }^{69}$, derechos sobre los fondos que constituyen el desahucio legal ${ }^{70}$, derechos emanados de un contrato de prestación de servicios educacionales ${ }^{71}$, derechos sobre permisos de

${ }^{65}$ Corte Suprema, Rol No 2545-2004.

${ }^{66}$ Corte Suprema, Rol No 1762-2004.

${ }^{67}$ Véase Roles Nos. 5503-2004 y 307-2005.

${ }^{68}$ Corte Suprema, Rol No 1852-2004. En esta materia, pueden citarse centenares de decisiones en los años posteriores, como se explicará.

${ }^{69}$ Vid. Roles $\mathrm{N}^{\circ}$ s. 823-2005 y 4286-2004. En materia de sanción a autotutela de arrendador que corta suministro de energía eléctrica vid. Corte Suprema, Rol No 2454-2007.

${ }^{70}$ Corte Suprema, Rol No 1042-2005.

${ }^{71}$ Corte Suprema, Rol No 3464-2005. Más recientemente, Roles Noos. 3071-2011, 28.4 .11 y $11944-$ 2011, 20.12.11. 
edificación ${ }^{72}$, derechos sobre concesión para extracción de áridos ${ }^{73}$, concesión marítima $^{74}$ o municipal $^{75}$, derecho a ser mantenido como presidente de un sindicato $^{76}$, derecho de uso que nace de un contrato de comodato ${ }^{77}$, de un contrato de cuenta corriente bancaria ${ }^{78}$, contrato de seguro ${ }^{79}$, etc. También puede citarse casos en que se ha estimado como ilegal la retención de devolución de impuestos ${ }^{80}$ e igualmente diversos actos municipales, tales como la cancelación ilegal de patente municipal ${ }^{81}$ o el cobro ilegal de derechos municipales ${ }^{82}$.

\section{Propiedad sobre otros derechos de contenido patrimonial}

Durante los años 2004 y 2005, la Corte Suprema acogió dos recursos de protección por vulneración de la propiedad sobre derechos vinculados a la imagen.

El primero, fue presentado por el padre de un destacado tenista y dirigido en contra de una tienda comercial, por haber usado ésta la imagen del deportista en campañas publicitarias, sin su autorización ${ }^{83}$. Al respecto, la Corte falló que la imagen corporal es un atributo de la persona, sobre la cual se tiene un derecho de propiedad. En consecuencia, el uso de su reproducción por cualquier medio con fines publicitarios o lucrativos corresponde a su titular.

\footnotetext{
${ }^{72}$ Corte Suprema, Rol No 3342-2005. También se ha sancionado la negativa injustificada de otorgamiento de patente (Corte Suprema, Roles Nos. 2697-2006 y 5503-2005).

${ }_{73}$ Corte Suprema, Rol No 3266-2005. En materia de concesión, más recientemente, Rol № 10963 2011, 2.12.11.

${ }^{74}$ Corte Suprema, Rol No 3157-2011, 7.6.11.

75 Corte Suprema, Rol No 2228-2011, 18.5.11.

${ }^{76}$ Corte Suprema, Rol No 5847-2005.

77 Corte Suprema, Rol No 5846-2005.

${ }^{78}$ Corte Suprema, Rol No 8248-2010, 25.1.11.

79 Corte Suprema, Rol No 872-2011, 25.3.11.

${ }^{80}$ Corte Suprema, Rol No 1478-2011, 24.3.11.

${ }^{81}$ Corte Suprema, Roles Nos. 7399-2011, 19.8.11 y 9210-2011, 14.10.11.

${ }^{82}$ Corte Suprema, Rol No 1707-2011, 30.3.11.

${ }^{83}$ Corte Suprema, Rol No 5502-2004.
} 
Otro recurso de similares características fue acogido el $2005^{84}$, en el que se reiteró la idea del derecho de propiedad sobre la imagen corporal.

Recientemente, se ha estimado como una infracción constitucional la utilización sin autorización de la imagen de una persona por parte de un medio de comunicación escrito. ${ }^{85}$

Finalmente una fuente importante de recursos acogidos por vulneración de esta facultad, es aquella que dice referencia con derechos emanados de relaciones laborales, especialmente aquellas que tienen como antecedente vínculos de carácter administrativo propios del sector público. $\mathrm{Al}$ respecto se ha alegado propiedad sobre un nombramiento a contrata ${ }^{86}$ y sobre un cargo municipal ${ }^{87}$. Del mismo modo, se ha sancionado el término de una contrata por simple oficio, sin cumplir con los procedimientos administrativos correspondientes ${ }^{88}$. También se han estimado inconstitucional la suspensión del pago de remuneraciones ${ }^{89}$ y de beneficios ${ }^{90}$ y el desconocimiento de derechos funcionarios consagrados en la ley y, en especial, la estabilidad en el empleo ${ }^{91}$.

${ }^{84}$ Corte Suprema, Roles Nos. 3064-2005 y 4393-2006.

85 Corte de Apelaciones de Santiago, Rol No 2214-2008, confirmado por la Corte Suprema (Rol No 4407-2008).

${ }^{86}$ Corte Suprema, Rol No 832-2005.

${ }^{87}$ Vid. Roles Nos. 932-2005 y 5909-2005.

${ }^{88}$ Corte Suprema, Rol No 838-2005.

${ }^{89}$ Corte Suprema, Rol No 1912-2005. El año 2011 pueden citarse diversas decisiones en que se declara la ilegalidad del descuento de remuneraciones sin instruir los respectivos sumarios (Roles Nos. 1467$11,25.4 .11 ; 5310-11,21.6 .11$ y 8418-11, 17.11.11). También en relación a municipios existen pronunciamientos (Roles Nos. 7140-2011, 19.11.11; 10.387-2011, 24.11.11 y 10.695-2011, 23.12.11). Tratándose de descuento de horas injustificada, Rol No 2283-2011, 29.6.11.

${ }^{90}$ Corte Suprema, Rol No 6414-2007. También se ha tutelado el desconocimiento de un grado incorporado al patrimonio (Corte Suprema, Rol No 4756-2007). En materia de negativa del pago de beneficios y asignaciones otorgadas por acto administrativo, pueden mencionarse más recientemente diversas decisiones de la Corte Suprema efectuadas durante el año 2011, especialmente dirigidas en contra de la Tesorería (Roles Nos. 3954-11, 24.5.11; 3575-11, 21.6.11; 5235-11, 1.8.11; 4787-11, 3.8 .11 ; 9769-11, 17.11.11 y 11629-11, 16.12.11). Igualmente, respecto de municipios (Roles 12772011, 27.1.11 y 5375-2011, 18.10.11).

${ }^{91}$ Corte Suprema, Rol No 535-2005. En materia de término unilateral de contratos durante 2011, Roles Nos. 884-11, 1.3.11; 1252-11, 20.4.11 y 1336-11, 20.4.11. También lo ha habido respecto de la negativa de reincorporación de funcionario contrariando dictamen de la CGR (Rol No 878-2011, 1.4.11). 


\section{LA PROTECCIÓN SOBRE DERECHOS NO TUTELADOS}

Como se sabe, el artículo 19 de la Constitución Política reconoce a las personas diversos derechos, desde la vida a la propiedad, pasando por la igualdad, el honor, la libertad, etc.

Pues bien, el artículo 20 garantiza con el recurso de protección a la mayoría de los mismos, salvo los denominados derechos sociales y económicos, como es el caso del derecho a la protección de la salud, de educación y de seguridad social. ${ }^{92}$

En el informe final de la Comisión de Estudio (CENC) se señaló sobre esta materia que "Es evidente que el recurso de protección no puede hacerse extensivo a derechos que, aunque reconocidos constitucionalmente, dependen para su debida satisfacción, de la capacidad económica del Estado o de las potencialidades culturales de la población, como sucede con el derecho a la educación, a la salud, a la seguridad social u otros". ${ }^{3}$

Sin embargo, nuestros tribunales superiores, y en particular la Corte Suprema, han tratado de dar debida tutela a situaciones abusivas en que en principio se invocan derechos no protegidos. Resulta, entonces, interesante analizar la forma que han buscado los tribunales para dar tutela indirecta a los mismos, en especial, a través de la aplicación indirecta de otros derechos. En particular se ha recurrido de manera frecuente al derecho de propiedad (fenómeno que ciertos autores califican como "propietarización de los derechos" ${ }^{94}$ ) y a la igualdad ante la ley. ${ }^{95}$

\section{Frente al derecho a la protección de la salud}

Como se ha señalado, el artículo 19 No 9 garantiza el derecho a la protección de la salud, imponiéndole ciertos deberes al Estado, tales como los de protección de las acciones de salud, la coordinación y control de las mismas y el

\footnotetext{
${ }^{92}$ Sobre la materia vid. SоTO KLOSS, Eduardo, "El recurso de protección, institución esencial de una sociedad libre", en 20 años de la Constitución Chilena 1981-2001, Santiago (2001), Ed. Navarro B., Enrique, pp. 421 y ss.

${ }^{93}$ Informe Final de la CENC, en RCHD 8 (11981), p. 235.

${ }^{4}$ Vid. Vergara Blanco, Alejandro, La propietarización de los derechos. Propiedad sobre los derechos, Informe Constitucional 322 (junio, 1992). En respuesta, Eduardo Soto Kloss, Propietarización de los derechos. No una "herejía" sino la "esencia" de lo que es derecho, Informe Constitucional 329 (junio, 1992).

95 Vid. NaVARro B., Enrique, Limites al recurso de protección en materia contractual, UFT 6 (2002), p. 56.
} 
garantizar su ejecución. Sólo se ampara el derecho a elegir el sistema de salud, ya sea público o privado. ${ }^{96}$

En el caso de este derecho y frente a su afectación, particularmente por terceros (en especial, instituciones de salud previsional) se ha recurrido al derecho de propiedad sobre los derechos que emanan de los contratos o la no discriminación arbitraria. Así, ya en 1989, se resolvía que la negativa arbitraria de una isapre a otorgar la cobertura pactada contractualmente importaba privación de la legítima percepción de un beneficio pecuniario que se ha incorporado al patrimonio del recurrente. ${ }^{97}$

Sin perjuicio de que, en otros casos, se ha estimado derechamente que se está invitando a abandonar el sistema por lo que se vulneraría la libertad de elección del sistema de salud, reconocido en el inciso final del artículo 19 No 9 y que sí se encuentra protegido.

En el último tiempo han sido reiterados los fallos sobre la materia, sancionándose el término unilateral del contrato ${ }^{98-99}$; el alza injustificada de los planes de salud ${ }^{100}$ o la negativa a cubrir cobertura ${ }^{101-102}$, todos ellos por parte de la institución de salud (Isapre) respectiva.

En recientes decisiones se ha enfatizado que la facultad revisora de las isapres "debe entenderse condicionada en su esencia a un cambio efectivo y plenamente comprobable del valor económico de las prestaciones médicas, en razón de una alteración sustancial de los costos y no por un simple aumento debido a fenómenos inflacionarios o a la injustificada posición de que la variación pueda estar condicionada por la frecuencia en el uso del sistema, pues es de la esencia de este tipo de contrataciones la incertidumbre acerca de su utilización". ${ }^{103}$ De este modo,

\footnotetext{
${ }^{6}$ Sobre la materia vid. Bulnes A., Luz, "El derecho a la protección de la salud en la Constitución de 1980", AJ 4 (2001). Con anterioridad, Álvarez R., Sergio, "Aspectos del derecho a la protección de la salud como garantía fundamental de un Estado de Derecho", RDP 47/48 (1990), p. 219.

${ }^{97}$ Corte Suprema, 22.05.89, GJ 107, p. 20.

${ }^{98}$ Corte de Apelaciones de Santiago, Rol No 5698-2001.

${ }^{99}$ En el mismo sentido, Corte Suprema, Rol No 3742-2002.

${ }^{100}$ Corte de Apelaciones de Santiago, Rol No 3656-2002. En el año 2006, vid. Corte Suprema Roles Nos. 3902 y 6498.

${ }^{101}$ Corte de Apelaciones de Concepción, Rol No 414-2002.

102 En el mismo sentido, Corte Suprema, Rol No 3552-2002. Lo mismo se ha reiterado en los años 2006 (Roles Nos. 2467 y 4486) y 2007 (Roles Nos. 5891 y 5628).

${ }^{103}$ Corte Suprema, Rol No 601-2011, 28.1.2011.
} 
también se ha señalado, debe tratarse de una alteración "objetiva y esencial de las prestaciones, apta para afectar a todo un sector de afiliados o, al menos, a todos los que contrataron el mismo plan". ${ }^{104}$ También se ha puntualizado que la facultad para determinar unilateralmente el precio de prestaciones relativas a garantías explícitas en salud sólo estará legitimada "cuando obedezca a una variación sobre la base de criterios objetivos de razonabilidad, servicio público y determinada en el costo de la cobertura de que se trata". ${ }^{105}$

Finalmente, como consecuencia de la declaración de inconstitucionalidad de una disposición por parte del Tribunal Constitucional, se ha entendido por la Corte Suprema, que las alzas por aplicación de las tablas de factores de edad y sexo carecerían de valor, toda vez que la columna vertebral del sistema de reajustabilidad por aplicación de las referidas tablas ha sido derogado. ${ }^{106}$

\section{Frente al derecho a la educación}

El artículo 19 No 10, como ya se explicó, reconoce el derecho a educación, en sus diversas etapas, lo que incluye desde la educación parvularia a la enseñanza media, imponiéndosele ello como un deber especial al Estado, habiendo sido esto último modificado constitucionalmente. ${ }^{107}$

Este derecho, como se sabe, tampoco se encuentra tutelado, a pesar de las obligaciones que se imponen al Estado en tal sentido. ${ }^{108}$

En el caso de acciones que afectan, en el hecho, el derecho a la educación (fundamentalmente por medidas adoptadas por establecimientos educacionales), los tribunales han entendido como infringido el derecho de propiedad sobre la matrícula o, en su caso, la no discriminación arbitraria.

A fines de la década de los ochenta encontramos sentencias que rechazan las acciones, sosteniendo que la conculcación del derecho a la educación, al estar

${ }^{104}$ Corte Suprema, Rol No 192-2011, 28.1.2011.

105 Corte Suprema, Rol No 9044-2010, 24.2.2011.

106 Corte Suprema, Rol No 566-2011, 17.2.2011.

107 Navarro B., Enrique, "Las Constituciones Chilenas en el siglo XX y sus reformas", en 20 años de la Constitución Chilena (2001), pp. 19-36.

108 Vid. GaETe R., Sergio, "El derecho-deber a la educación”, Revista de Derecho Público 41/42 (1987), p. 231 y OOREGo S., Cristóbal, "El derecho a la educación y la libertad de enseñanza en la Constitución de 1980”, RCHD 13 (1986), p. 463. 
excluida de la protección constitucional, no puede razonarse sobre la base de otros derechos. ${ }^{109}$ Del mismo modo se denegaba la posibilidad de invocar el derecho de propiedad sobre los títulos profesionales, dado que no participarían del carácter de bienes incorporales. ${ }^{110}$

Sin embargo, casi dos años después, se sostiene por nuestro máximo tribunal que la calidad de estudiante universitario faculta al interesado para acceder al título, lo que configura una especie de propiedad, que se encuentra amparada en el artículo 19 No 24 de la Constitución Política ${ }^{111}$; lo que también se ha señalado en los últimos años. ${ }^{112}$

Por su lado, en la misma época, la Corte de Santiago estimaba infringido el artículo 19 No 2 al expulsarse a un alumno sin seguir el procedimiento fijado por el estatuto reglamentario. ${ }^{113} \mathrm{El}$ año 2011, la Corte Suprema acogió diversas acciones en las que se estimó como ilegales diversas decisiones en que se impidió la continuación de los estudios. ${ }^{114}$

De igual forma, se ha resuelto que la negativa de un establecimiento educacional de entregar certificado de notas y estudio vulnera el derecho de propiedad del recurrente sobre "los logros académicos". 115

\section{Frente al derecho a la seguridad social}

El artículo 19 No 18 de la Constitución resguarda el derecho a la seguridad social, precisándose que las leyes que regulen su ejercicio serán de quórum calificado. En este caso, como se analizó, la acción del Estado debe estar dirigida a garantizar el acceso a las personas al goce de las prestaciones básicas uniformes, sea que se otorguen a través de instituciones públicas o privadas. Del mismo modo, se impone al Estado el deber de supervigilar el adecuado ejercicio de

${ }^{109}$ Corte Suprema, 26.05.87, RDJ 84, p. 173.

${ }^{110}$ Corte Suprema, 28.07.81, RDJ 78, p. 142.

111 Corte Suprema, 6.04.89, GJ 106, p. 27.

112 Corte de Apelaciones de Santiago, Rol No 1182-2001.

113 Corte de Apelaciones de Santiago, 18.12.89, GJ 114, p. 40.

${ }^{114}$ Entre otros, Roles Nos. 1271-2011, 7.4.11; 6788-2011, 25.8.11; 9105-2011, 19.10.11, 9878-2011, 27.10.11 y 10705-2011, 22.11.11.

115 Corte de Apelaciones de Talca, Rol No 60845. 
este derecho. Dado su naturaleza prestacional, este derecho tampoco encuentra protección directa constitucional. ${ }^{116}$

Sobre esta materia, la Corte de Apelaciones de Santiago -a principios de los noventa- hacía presente que, al no encontrarse protegido constitucionalmente este derecho, no era posible obtener por esta vía tutelar la declaración de que determinados hechos revisten el carácter de accidentes del trabajo. ${ }^{117}$ Sin embargo, meses antes, la Corte Suprema precisaba que el desconocimiento por la autoridad previsional del acrecimiento de la pensión de montepío importa una vulneración del derecho de propiedad. ${ }^{118}$ Del mismo modo, se ha sentenciado que los beneficios de una pensión de jubilación, debidamente reajustados, forman parte del patrimonio de la persona y están amparados por el artículo 19 No 24 de la Carta Fundamental. ${ }^{119}$

Como puede observarse, frente a situaciones inicuas, en donde aparentemente se ven afectados derechos no tutelados expresamente, nuestra Corte Suprema ha preferido dar protección efectiva, principalmente estimando vulnerado el derecho de propiedad. ${ }^{120}$

\section{Antecedentes del Auto Acordado \\ 1. Dictación del primer Auto Acordado}

La Corte Suprema por Auto Acordado de 29 de marzo de 1977 regula por primera vez la tramitación de esta acción. ${ }^{121}$

Sabido es que el Acta Constitucional No 3 de 1976 contenía referencia explícita a la facultad de la Corte Suprema para dictar un Auto Acorda-

116 Costa R., Vasco, "Derechos laborales y Constitución de 1980", en 20 años de la Constitución Chilena (2001), Ed. Navarro B., Enrique; pp. 287 y ss.

117 Corte de Apelaciones de Santiago, 12.04.90, GJ 118, p. 26.

${ }^{118}$ Corte Suprema, 25.10.89, RDJ 86, p. 153.

${ }^{119}$ Corte de Apelaciones de Santiago, 28.08.86, Revista de Derecho y Jurisprudencia 83, p. 185.

120 Una visión más completa en Navarro Beltrán, Enrique, "Soluciones jurisprudenciales a desprotecciones constitucionales", Actas de las XXXIV JDP, Ed. LexisNexis (2005); pp. 291-294. Más recientemente, "Protección constitucional de los derechos sociales en Chile", en Anuario de Derecho Constitucional Latinoamericano (2010), pp. 273-288.

${ }^{121}$ Publicado en el Diario Oficial de fecha 2 de abril de 1977. 
do. ${ }^{122}$ Similar disposición se contenía en el Anteproyecto de la Comisión de Estudio. ${ }^{123}$

En el seno de la CE se produjo una interesante discusión acerca de la eventual supresión de la atribución para arbitrar lo necesario con el objeto de hacer rápido y eficaz el procedimiento: "En primer lugar, porque tiene esa facultad; en segundo término, porque significa alargar innecesariamente la disposición, y, en tercer lugar, porque podría entenderse que en otros casos, al no decirlo expresamente, la Corte Suprema no tendría dicha facultad". ${ }^{124}$

En definitiva, en el Consejo de Estado se acordó suprimir el inciso final, teniendo en consideración lo manifestado por el señor Philippi, quien sostuvo que "la Corte Suprema posee la facultad de dictar autos acordados, por lo que si se establece tal atribución en la Carta Fundamental, podría llegarse a la absurda conclusión de que dicho auto acordado tiene jerarquia de norma constitucional". A su vez Enrique Ortúzar explicó que "en la fecha en que se redactó la norma observada, no se habia dictado aún ningún auto acordado sobre tan importante materia", por lo que "concuerda en que ahora el precepto resulta innecesario". ${ }^{125}$

Cabe recordar que sobre el punto, el profesor Eduardo Soto Kloss ha señalado que "en caso alguno podría entenderse que dicho Auto Acordado carece ahora de sustento normativo, pues, como vimos en el párrafo precedente, la Corte Suprema posee de suyo la potestad normativa para dictar auto acordados, tanto bajo la Constitución Politica de 1925 como ahora con la de 1980". 126

\section{Modificaciones posteriores}

Durante la vigencia de la Carta Fundamental de 1980 se le introducen diversas enmiendas al procedimiento.

En efecto, con fecha 24 de junio de 1992 se modifica el Auto Acordado, que en lo sustancial se refiere al recurso de apelación, ampliando su plazo

\footnotetext{
${ }^{122}$ Acta Constitucional 3, de 1976, artículo 2o inciso 20: "la Corte Suprema dictará un auto acordado que regule la tramitación de este recurso".

${ }^{123}$ Artículo 20 inciso 30: "la Corte Suprema dictará un auto acordado que regule la tramitación de este recurso".

124 CENC, sesión No 215.

125 Sesión No 65 de 13 de marzo de 1979.

126 Soto Kloss, Eduardo, El Recurso de Protección. Origenes, Doctrina y Jurisprudencia, Santiago, 1982, p. 230.
} 
a 5 días hábiles y estableciendo como regla general la vista de la causa en cuenta. ${ }^{127}$

A su turno, en 1998 se vuelve a modificar la tramitación de la acción, generando diversas críticas por parte de la doctrina. ${ }^{128}$ Principalmente se facultaba a la Corte de Apelaciones para analizar la admisibilidad de la acción, pudiendo la unanimidad de los integrantes declarar que la presentación había sido extemporánea o adolecía de manifiesta falta de fundamento. ${ }^{129}$ Del mismo modo, la apelación podía ser declarada inadmisible en caso de ser interpuesta fuera de plazo o no ser fundada ni contener peticiones concretas. ${ }^{130}$

Obviamente la discusión se acentúa con el incremento de las inadmisibilidades, en particular en Santiago, habida consideración de los más de 3000 ingresos anuales promedio. En todo caso, debe recordarse que dicha resolución debía ser unánime y motivarse, ya sea por extemporaneidad de la acción presentada o por manifiesta falta de fundamento de la misma.

Cabe señalar que a la fecha no se ha aprobado un texto legal que regule adecuadamente su tramitación. Baste citar los proyectos del senador Bombal de 1998 (y que se encuentra archivado) ${ }^{131}$ y de los diputados Martínez, Bustos, Cardemil, Elgueta, Luksic, Soto, Bartolucci y Rocha, de 2001, que es más amplio y contenido en 63 artículos. ${ }^{132} \mathrm{El}$ año 2005 ingresó otro proyecto, del actual senador Navarro, quien propone un plazo de seis meses para deducir la acción cautelar, con una tramitación similar a la anterior a la reforma del auto acordado. ${ }^{133}$

\section{La modificación de 2007}

El año 2007, por acuerdo del Pleno de la Corte Suprema, se modifica la tramitación del recurso de protección. ${ }^{134}$

\footnotetext{
${ }^{127}$ Auto Acordado publicado en el Diario Oficial de fecha 27 de junio de 1992.

128 Vid. RUFT 2 (1998), pp. 59 y ss.

${ }^{129}$ Inciso $2^{\circ}$ del artículo 2 del AA.

${ }^{130}$ Artículo 6 del AA.

${ }^{131}$ Boletín No 2191-07. Archivado.

${ }_{132}$ Boletín No 2809-07. En primer trámite constitucional (Comisión de Constitución, Legislación y Justicia).

${ }^{133}$ Boletín No 4011-07. En primer trámite constitucional.

${ }^{134}$ Acta No 70-2007, publicada en el Diario Oficial de 8 de junio de 2007.
} 
En primer lugar se amplía su plazo a 30 días. Así se ha duplicado el mismo, lo que debería facilitar su interposición, teniendo sí presente que debe contarse el mismo desde que se ha tenido conocimiento de la acción u omisión, presentando esta última situación obviamente mayor dificultad.

A su vez, se elimina el trámite de inadmisibilidad por manifiesta falta de fundamento y, en su lugar, se debe revisar si en la presentación se mencionan hechos que puedan constituir vulneración de las garantías constitucionales.

Los tribunales han ido decantando ciertos principios a tener en consideración sobre el punto. Entre otros, cabe mencionar el que esta acción no resulta idónea para discutir materias de lato conocimiento, propias de un juicio ordinario ${ }^{135}$, su limitación respecto de situaciones cuya arbitrariedad e ilegalidad sean evidentes ${ }^{136}$, su improcedencia para declarar o constituir situaciones jurídicas nuevas ${ }^{137}$ o declarar derechos permanentes a favor de las partes ${ }^{138}$.

Del mismo modo, de acuerdo a las recientes modificaciones el recurso de apelación ya no debe ser fundado ni contener peticiones concretas, como se había exigido a partir de 1998.

Por último, se establece que en segunda instancia la Corte Suprema oirá alegatos, especialmente, cuando se pida de común acuerdo por las partes.

Cabe destacar recientes decisiones del máximo tribunal. En efecto, en cuanto a su interposición, a través de una decisión de oficio, se ha insistido que en la admisibilidad no se puede recurrir a alegaciones de fondo, como era usual. ${ }^{139}$ Igualmente, se ha sido más amplio y menos formal en lo relativo al plazo. ${ }^{140}$

\footnotetext{
${ }^{135}$ Corte Suprema, 22 de junio de 1992, GJ 144, p. 57. En el mismo sentido, Corte Suprema, 26 de junio de 1995, GJ 180, p. 24.

${ }^{136}$ Corte Suprema, 9 de julio de 1993, GJ 159, p. 180.

${ }^{137}$ Corte Suprema, 8 de octubre de 1997, GJ 208, p. 38.

${ }^{138}$ Corte Suprema, 24 de enero de 1991, GJ 127, p. 20.

${ }^{139}$ Corte Suprema, Rol No 3296/2012.

${ }^{140}$ Corte Suprema, Rol No 3193/2012. Se ha señalado, en todo caso, que el plazo debe ser enteramente objetivo, sujeto a parámetros conocidos, sin que pueda quedar al arbitrio del recurrente (Corte Suprema, Rol No 145-2010, 27.1.2010).
} 


\section{JURISPRUdencia DEL TRIBUnAL CONSTITUCIONAL EN RELACión al Auto Acordado de protección}

\section{Reforma constitucional de 2005}

La reforma constitucional de 2005 entregó al Tribunal Constitucional la facultad de revisar determinados autos acordados emanados de los tribunales superiores de justicia.

En cuanto a la naturaleza jurídica de los autos acordados se ha sentenciado que debe tratarse de actos de carácter "general y abstracto" y no de simple resoluciones administrativas. ${ }^{141}$ Esto es, "un cuerpo de normas generales y abstractas, dictado generalmente por tribunales colegiados (Corte Suprema, Cortes de Apelaciones y Tribunal Calificador de Elecciones), con el objeto de imponer medidas o impartir instrucciones dirigidas a velar por el más expedito y eficaz funcionamiento del servicio judicial”. ${ }^{142}$

\section{Antecedentes de los autos acordados}

La Constitución de 1823 le otorga a la Suprema Corte -que se establece ese mismo año- la "superintendencia directiva, correccional, económica y moral ministerial, sobre los tribunales y juzgados de la Nación” (artículo 148). En el mismo sentido, la Constitución de 1828 establece como atribución de la Corte Suprema "ejercer la superintendencia directiva, correccional, consultiva y económica sobre todos los tribunales y juzgados de la Nación" (artículo 96, No 10).

Luego, la Carta de 1833 reiteró que habrá en la República una magistratura - la Corte Suprema, ya establecida diez años antes- a cuyo cargo está "la superintendencia directiva, correccional y económica sobre todos los tribunales y juzgados de la Nación, con arreglo a la ley que determine su organización y atribuciones" (artículo 113).

Esta última, que se dictará en 1875 , le entrega una vez más a la Corte Suprema "la jurisdicción correccional, disciplinaria y económica sobre todos los tribunales de la Nación" (artículo 108).

Al estudiarse esta normativa, se dejó constancia que "los tribunales podian, a consecuencia de las atribuciones que se les da en lo económico, dictar lo que

${ }^{141}$ TC, Rol No 1009, 8.04.2008.

142 TC, Rol No 1557, 14.04.2011. 
se llama auto acordados, así como tomar medidas o adoptar disposiciones de carácter general relativas a la policía judiciaria". ${ }^{143} \mathrm{El}$ mismo autor expresa que los referidos autos acordados "son medidas de carácter general, encaminadas al cumplimiento exacto de las disposiciones legales vigentes. En ningún caso podría acordar reglamentos o decretos, que invadiesen las facultades de los otros poderes constitucionales". ${ }^{144}$

Por último, la Carta de 1925 indica que la Corte Suprema "tiene la superintendencia directiva, correccional y económica de todos los tribunales de la Nación, con arreglo a la ley que determine su organización y atribuciones" (artículo 86).

En concordancia con lo señalado en el artículo 82 de la actual Carta Fundamental, el artículo 96, No 4, del Código Orgánico de Tribunales dispone que corresponde al Pleno de la Corte Suprema: "Ejercer las facultades administrativas, disciplinarias y económicas que las leyes le asignan (.... ). En uso de tales facultades, podrá determinar la forma de funcionamiento de los tribunales y demás servicios judiciales, fijando los días y horas de trabajo en atención a las necesidades del servicio".

Así, por lo demás, fue explicitado por el TC en diversas sentencias que se pronunciaron respecto de requerimientos interpuestos respecto de Autos Acordados. ${ }^{145}$

Se ha estimado que se ajusta a la Carta Fundamental el auto acordado que regula la tramitación del recurso de protección y que señala la forma en que procede la vista de la causa en segunda instancia ${ }^{146}$ y la condena en $\operatorname{costas}^{147}$.

\section{3. Ámbito de los autos acordados}

Se estableció que "en aspectos de funcionamiento en que el legislador no ha establecido normas o que expresamente no le ha reservado a éste, el propio órgano judicial puede auto regularse", haciendo presente que "naturalmente

\footnotetext{
${ }^{143}$ Egidio Ballesteros, Manuel, La Ley de Organización y Atribuciones de los Tribunales de Chile, Tomo I, 1890 , p. 18.

${ }^{144}$ Ibid., p. 539.

145 TC, Roles Nos. 783/2007; 1557/2009, y 1812, 1816 y 1817/2010.

${ }^{146}$ TC, Roles Nos. 1812, 1816 y 1817.

147 TC, Rol No 1557, 14.4.2011.
} 
estas regulaciones no pueden contradecir normas legales ni menos las de rango constitucional". Por ende, se concluye que "los autos acordados no pueden regular materias que el constituyente ha reservado al legislador". ${ }^{148}$

Obviamente los tribunales de justicia pueden "en materias disciplinarias de su competencia, precisar su propio funcionamiento, dictando normas reglamentarias ante la falta de normas legales, a través de un auto acordado". ${ }^{149}$

De este modo, "en aspectos de funcionamiento en que el legislador no ha establecido normas o que expresamente la Constitución no le ha reservado a éste, el propio órgano judicial puede autoregularse. Impedirlo haría imposible o enteramente discrecional el ejercicio de la facultad disciplinaria. Un Poder Judicial independiente y responsable de prestar un buen servicio a todas las personas, puede, a través de sus autoridades, regular el ejercicio de sus facultades disciplinarias por medio de autos acordados. Naturalmente estas regulaciones no pueden contradecir normas legales ni menos las de rango constitucional”. ${ }^{150}$

\section{Decisiones del TC en relación al Auto Acordado}

Se ha estimado que se ajusta a la Carta Fundamental el auto acordado que regula la tramitación del recurso de protección y que señala la forma en que procede la vista de la causa en segunda instancia ${ }^{151}$ y la condena en costas. ${ }^{152}$

Cabe tener presente que el único cuerpo normativo declarado inconstitucional -en parte- en este período es el auto acordado dictado por la Corte de Apelaciones de Santiago y que decía relación con el procedimiento disciplinario aplicable a los jueces inferiores, cuestionándose la circunstancia de que contemplare una etapa secreta durante la investigación sumarial. ${ }^{153} \mathrm{La}$ Corte Suprema posteriormente dictó una nueva normativa aplicable a todos los tribunales de justicia.

148 TC, Rol No 783, 31.08.2007, consid. 25. Antecedentes de los autos acordados en NaVArro Beltrán, Enrique, Los autos acordados y la reforma de 2006, Colegio de Abogados de Chile, 2006.

${ }^{149}$ Ibid., consid. 29.

150 TC, Rol No 1568, 16.11.2010.

${ }^{151}$ TC, Roles Nos. 1812, 1816 y 1817.

152 TC, Rol No 1557, 14.04.2011.

153 TC, Rol No 783, 31.08.2007. 


\section{CONCLUSIONES}

De lo dicho puede concluirse lo siguiente:

1. La acción de protección se remonta en cuanto a sus antecedentes históricos en Chile en las facultades protectoras que ejercieron los tribunales de justicia hasta 1874. En Hispanoamérica, especial influencia ejerció el amparo mexicano de mediados del siglo XIX.

2. Su establecimiento se produce en 1976, en virtud del Acta Constitucional No 3, pasando luego a la Carta Fundamental de 1980, en los términos que indica el actual artículo 20, modificado el año 2005, en relación al derecho a vivir en un medio ambiente libre de contaminación.

3. Se trata de una acción de gran importancia, lo que se demuestra con su aumento explosivo de unas pocas decenas a fines de los setenta a más de treinta mil anuales -en la actualidad-y vinculados a bienes jurídicos tan fundamentales como la vida, igualdad, privacidad, libertad y propiedad.

4. Existe una fuerte tendencia a resolver los conflictos de protección a través del derecho de propiedad, entendido en relación ya sea a cosas corporales como incorporales. Incluso, se ha estimado que existe propiedad sobre ciertos derechos de contenido patrimonial, como la imagen, el derecho al título o la propiedad sobre el cargo.

5. Debe destacarse también el sentido garantístico que se le ha dado a esta acción por parte de los tribunales, particularmente frente a situaciones en principio no tuteladas (como la salud, educación y seguridad social), recurriendo a otros derechos fundamentales, como la propiedad o la igualdad ante la ley.

6. La acción de protección se encuentra regulada en un Auto Acordado, dictado por la Corte Suprema en 1977, modificado en 1992, 1998 y, recientemente, el 2007. Esta última amplía el plazo a 30 días, elimina el trámite de admisibilidad por falta de fundamento y simplifica el recurso de apelación. El Tribunal Constitucional ha estimado que no son contrarias a la Carta Fundamental, las disposiciones del Auto Acordado que regulan la vista de la causa en segunda instancia y la condena en costas.

7. Las reformas al Auto Acordado realizadas el año 2007, al ampliar su plazo de interposición y simplificar su tramitación, permitieron acrecentar la tutela efectiva de los derechos constitucionales, afectados por actos u omisiones ilegales o arbitrarias, de autoridad o particulares, fortaleciendo así este recurso, verdadera "revolución silenciosa", como lo calificara un autor, a 30 años de su establecimiento efectivo. 


\section{Abreviaturas usadas}

$\begin{array}{ll}\text { AJ } & \text { : Revista Actualidad Jurídica U. del Desarrollo) } \\ \text { CE } & \text { : Consejo de Estado } \\ \text { CECOCH } & \text { : Revista del Centro de Estudios Constitucionales (U. de Talca) } \\ \text { CENC } & \text { : Comisión de Estudio de la Nueva Constitución } \\ \text { CPR } & \text { : Constitución Política de la República } \\ \text { CS } & \text { : Corte Suprema } \\ \text { FM } & \text { : Fallos del Mes } \\ \text { GJ } & \text { : Gaceta Jurídica } \\ \text { IEP } & \text { : Revista Ius et Praxis (U. Talca) } \\ \text { IP } & \text { : Ius Publicum (U. Santo Tomás) } \\ \text { JDP } & : \text { Jornadas de Derecho Público } \\ \text { RCS } & : \text { Revista de Ciencias Sociales (U. de Valparaíso) } \\ \text { RCHD } & : \text { Revista Chilena de Derecho (U. Católica) } \\ \text { RD } & : \text { Revista de Derecho (U. de Concepción) } \\ \text { RDJ } & : \text { Revista de Derecho y Jurisprudencia } \\ \text { RDP } & : \text { Revista de Derecho Público (U. de Chile) } \\ \text { P } & : \text { Política (Instituto de Ciencia Política, U. de Chile) } \\ \text { TC } & : \text { Tribunal Constitucional } \\ \text { TD } & : \text { Temas de Derecho (U. Gabriela Mistral) } \\ \text { UFT } & : \text { Revista de Derecho de la U. Finis Terrae } \\ \text { UM } & : \text { Revista de Derecho U. Mayor }\end{array}$

